\title{
ANTIUROLITHIATIC ACTIVITY OF ETHANOLIC EXTRACT OF TAXILLUS TOMENTOSUS PLANT ON ETHYLENE GLYCOL AND AMMONIUM CHLORIDE INDUCED UROLITHIASIS IN WISTAR RATS
}

\author{
Kambham Venkateswarlu ${ }^{1 *}$, Jami Komala Preethi ${ }^{2}$, K.B. Chandrasekhar 3
}

\begin{abstract}
1Dept. Pharmaceutics, JNTUA-Oil Tech. and Pharm. Res. Institute, Jawaharlal Nehru Technological University Anantapur, Andhra Pradesh, India. 515001

${ }^{2}$ Graduate Student, JNTUA-Oil Tech. and Pharm. Res. Institute, Jawaharlal Nehru Technological University Anantapur, Andhra Pradesh, India. 515001

${ }^{3}$ Dept. Chemistry, JNTUA-Oil Tech. and Pharm. Research Institute, Jawaharlal Nehru Technological University Anantapur, Andhra Pradesh, India. 515001
\end{abstract}

Submitted: $11-1-2016$
Revised: 01-03-2016
Accepted: 28-03-2016
*Corresponding author
Kambham Venkateswarlu
Email:
k.v.reddy9441701016@gmail.com

\section{INTRODUCTION}

Presently, urolithiasis is the third most common disorder of the urinary tract. It is the presence of calculi in the urinary tract with male-to-female incidence ratio of four times and more among white males than in black males. Occurrence of kidney stones is more with increasing age and among men. In more than $50 \%$ of the patients, the disease usually reoccurs within ten years. Of all kidney stones, $85 \%$ contain calcium salts as their main crystalline components (calcium oxalate and/or calcium phosphate) (Hess, 2003). In some patients, chances of reoccurrence of stone is more due to the large amount of excretion or defective forms of crystallization inhibitors, which allows the formation of large crystal aggregates as stones precursors. Crystal adhesion to urothelial surfaces might be increased in stone formers (Karadi, et al., 2006). A less common type of stone is, because of infection in the urinary tract, called as struvite or infection stone. Uric acid stone is a bit less common and cystine stones occur rarely (Rivers, et al., 2000; Mitra, et al., 1998).

Research on etiology and prevention of stone disease in urinary tract had been directed in the direction of abnormal increase in urinary levels of calcium, oxalate and uric acid in formation of stone and reduces urinary citrate levels (Hongshi, et al., 2013). Citrate and magnesium are the main inhibitors of stone formation in the urinary tract and decreased levels or lack of these inhibitors in the urine causes stone formation (Fleisch, 1978). Cystinuria and hyperoxaluria (high concentrations of cystine and oxalate respectively) are two rare and inherited metabolic disorders that cause kidney stones (Vishal and Jack, 2011).

Taxillus tomentosus plant is one of the herbal plants belongs to the family of genus Taxillus was found in Maharashtra, Karnataka, Kerala, Tamilanadu, Andhra Pradesh and also in Srilanka. Previous studies reported that this 
plant have different pharmacological actions like antidiabetic, neuroprotective, hepatoprotective, cardioprotective (Mohammed, et al., 2015), nootropic, antistress activities (Silpa, Jamal and Jayasekhar, 2014). Now the present study was designed to evaluate the antiurolithiatic potency of EET'T against EG and AC induced urolithiasis in male wistar rats as such study using the plant extract was not reported earlier.

\section{MATERIALS AND METHODS \\ Collection of plant material and authentication}

The plant Taxillus tomentosus was collected from local areas of Tirumala hills, Tirupati, India and was authentified by Dr. M. Madhava chetty, Department of botany, Sri Venkateswara University, Tirupati, Andhra Pradesh, India (Prof. M. Madhava chetti, Department of botany, Sri Venkateswara University, Tirupati, Andhra Pradesh, India (Voucher number: 1616).

\section{Plant extraction}

The Taxillus tomentosus plants were collected and extraneous matter was removed, shade dried for 2 days. Then the dried material was powdered with a mechanical grinder and passed through sieve no. 40 and stored in an air tight container for further processing. The dried powdered material $(250 \mathrm{~g})$ was extracted with $95 \%$ ethanol using soxhlet apparatus for about $72 \mathrm{~h}$, concentrated by distilling the solvent and evaporated to dryness. The dried extract was subjected for experimental studies (Venkateswarlu et al., 2015). The percent yield was found to be $8.12 \mathrm{~g}$.

\section{Phytochemical analysis}

The EETT was analyzed for the presence of phytochemical constituents like tannins, flavonoids and alkaloids (Khandelwal, 2005).

\section{Drugs and chemicals}

Ethylene glycol (EG) (AR Grade) and Ammonium chloride (AC) were procured from Merck Laboratories, Mumbai, India. Cystone

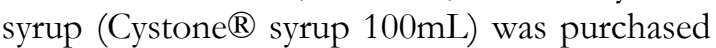
from Himalaya TM herbal health care, Bangalore, India.

\section{Experimental animals}

The male Wistar rats (of 200-250g) were procured from the central animal house of Sigma Institute of Clinical Research and Administration Pvt. Ltd, Hyderabad. Animals were well housed at a temperature $22 \pm 3^{\circ} \mathrm{C}$; relative humidity $30-70 \%$ and $12 \mathrm{~h}$ light/dark cycle was followed. All animals were allowed free access to water and standard pelleted laboratory animal diet. Animals were acclimatized to laboratory conditions one week before the experiment to be performed and all the procedures were approved by the Institutional Animal Ethical Committee (Ref. No. 769/2015) which was constituted according to the guidelines of Committee for the Purpose of Control and Supervision of Experiments on Animals (CPCSEA), India (Tandon et al., 2000).

\section{Acute oral toxicity study}

Acute toxicity studies were performed according to OECD Guideline No. 423 (short term toxicity). Wistar rats $(n=3)$ of either sex were selected by random sampling technique and kept in their cages for at least 5 days prior to the dosing to allow the acclimatization for laboratory conditions. If the mortality was observed in $2 / 3$ or $3 / 3$ of animals, then the dose administered was considered to be as a toxic dose. However, if the mortality was observed only in one animal out of three, then the same dose was repeated again to confirm the toxic effect.

\section{Urolithiasis induction}

In $0.75 \%$ of $\mathrm{EG}$ and $2 \%$ of $\mathrm{AC}$ were mixed well and dissolved in required amount of distilled water. This solution was prepared daily basis by considering the number and weight of animals and given orally as feed. Body weight of each animal was recorded daily (Touhami et al., 2007).

\section{Assessment of antiurolithiatic activity}

EG and AC induced urolithiasis model in wistar rats were divided into five groups containing 6 animals in each and kept in metabolic cages. All the experimental animals had free access to regular diet and drinking water ad libitum for 28 days. Normal group animals were had regular diet and drinking 
water ad libitum for 28 days. Control, standard and treated group animals (TGI \& TGII) were supplemented with $0.75 \% \mathrm{EG}$ and $2 \% \mathrm{AC}$ in distilled water ad libitum for 15 days and incase of standard group animals which were administered with CST $(5 \mathrm{~mL} / \mathrm{kg}$ BW) from $15^{\text {th }}$ day onwards to $28^{\text {th }}$ day. TGI and TGII animals were administered with EETT $200 \mathrm{mg} / \mathrm{kg}$ BW and EET'T $400 \mathrm{mg} / \mathrm{kg}$ BW respectively from $15^{\text {th }}$ onwards to $28^{\text {th }}$ day.

\section{Biochemical parameters}

The concentration of creatinine, calcium, uric acid, urea and oxalate was estimated in urine and serum by using diagnostic kits obtained from Robonik Diagnostics Ltd., India.

\section{Urine analysis}

Urine samples were collected on $28^{\text {th }}$ day (24h) and a drop of concentrated $\mathrm{HCl}$ was added prior to the storage. Urinary creatinine, calcium, uric acid, urea, oxalate contents and urine $\mathrm{pH}$, urine volume were estimated. Urine was centrifuged (Heraeus ${ }^{\circledR}$ Biofuse ${ }^{\circledR}$ pico, Kendro Laboratory Products $\mathrm{GmbH}$, Hanau) to pool the crystals and observed under the light electron microscope at $5 \mathrm{X}$ for knowing the size and shape of crystals (Patel $e t$ al., 2012).

\section{Serum analysis}

Blood was collected from retro orbital pluxes under anesthetic condition. The blood was centrifuged at $10.000 \mathrm{rpm}$ for $10 \mathrm{~min}$ to separate the serum and analyzed for creatinine, uric acid, urea and calcium oxalate contents (Parasuraman et al., 2010).

\section{Histopathology}

The either kidneys of each animal were collected/removed by making a cut to the abdomen. The extraneous tissue of isolated kidneys were cleaned off and preserved in 10\% neutral formalin solution. By using the conventional methods, one of the isolated kidneys was embedded in paraffin and was cut into thin sections of about $5 \mu \mathrm{m}$. These sections were stained with $\mathrm{H} \& \mathrm{E}$ dye and finally mounted in diphenyl xylene. Then these sections were observed under the microscope for knowing the changes in histopathology of kidney architecture and weight of the each kidney was determined (Hodgkinson, 1970).

\section{Statistical analysis}

All the data was expressed as mean $(\mathrm{n}=6) \pm$ SEM. Statistical significance between different groups was tested by two way ANOVA followed by Dunnett's multiple comparison test using computer based fitting program (GraphPad Prism version 6.04) and statistical significance was set at $\mathrm{p}<0.05$.

\section{RESULTS AND DISCUSSION Acute toxicity study}

Acute toxicity studies were conducted in wistar rats by dividing five groups containing six animals each shows the lethal dose and effective dose of the drug at safe levels for rats. $\mathrm{LD}_{50}$ cut-off doses at $2000 \mathrm{mg} / \mathrm{kg}$ body weight, indicating that the drug to be much safer and $1 / 10^{\text {th }}\left(200 \mathrm{mg} / \mathrm{kg}\right.$ of body weight) and $1 / 5^{\text {th }}$ ( $400 \mathrm{mg} / \mathrm{kg}$ of body weight) of LD50 dose were selected for further studies.

\section{Phytochemical analysis}

From the phytochemical analysis studies, it was found that the EETT consists of phytochemicals like flavonoids, alkaloids, tannins and flavonoids were present in high concentration when compared to the alkaloids and tannins (Figure 1).

\section{Urine analysis \\ Microscopic examination of Urine}

The microscopic examination $(5 \mathrm{x})$ has revealed that the urine of normal group animals was devoid of any crystals or similar structure (Figure 2(A)). Urine samples from urolithiatic rats (control group) showed abundant, large peritubular crystals of $\mathrm{CaOx}$ with characteristic rectangular shape scattered throughout (Figure 2(B)). The standard group animals showed few or almost dissolved small crystals or remnants (Figure 2(C)). On curative treatment, the EETT showed better dissolution of the preformed crystals of $\mathrm{CaOx}$ (Figure 2(D\&E)). However, small fragments of crystals were seen in both TGs and standard group.

\section{Evaluation of urine, blood and physiological parameters}

Effects of CST and EETT on urine and blood parameters of wistar rats (Table I and II). After urolithiasis induction, the parameters like creatinine, calcium, oxalate, urea, uric acid in urine and serum were remarkably increased in 


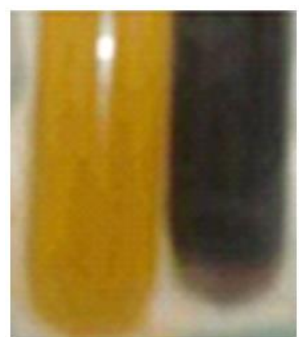

A. Tannins

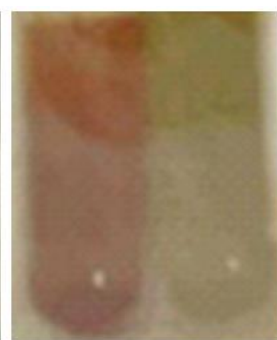

B. Alkaloids

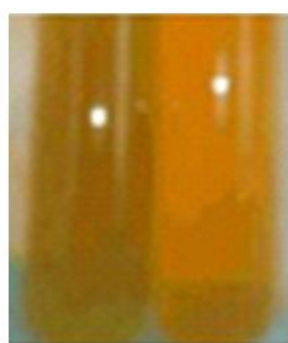

C. Flavonoids

Figure 1. nucleophilic addition of amine in $p$-aminophenol and vanillin, forming imine group in PAPVN structure
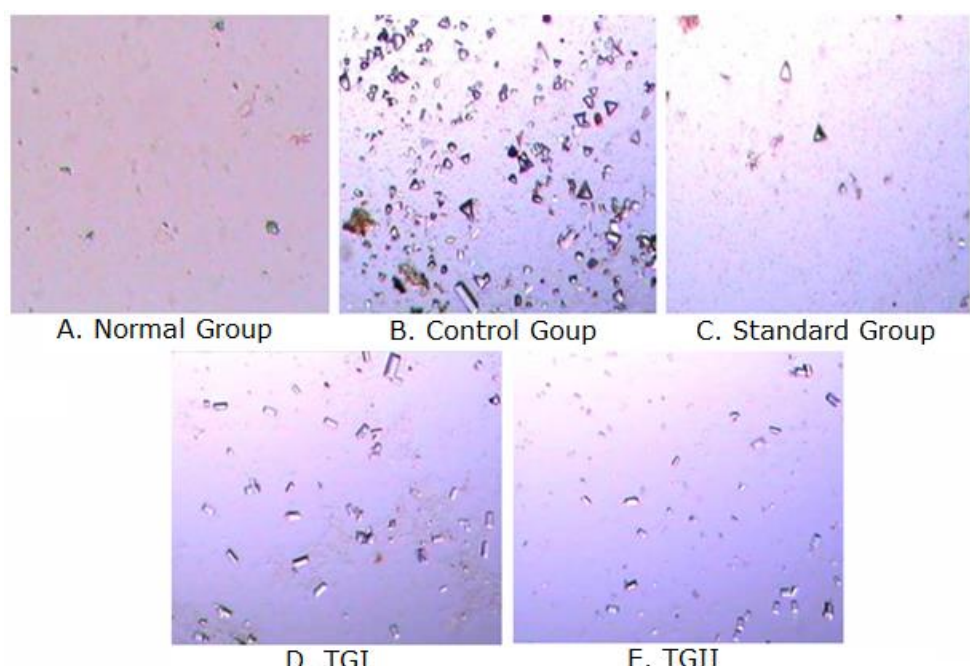

Figure 2. Microscopic observations of urine in various treatment groups.

Table I. Effect of EET'T on urine parameters in urolithiatic rats

\begin{tabular}{cccccc}
\hline \multirow{2}{*}{ Groups } & \multicolumn{5}{c}{ Urine parameters } \\
\cline { 2 - 6 } & $\begin{array}{c}\text { Creatinine } \\
(\mathbf{m g} / \mathbf{d L})\end{array}$ & $\begin{array}{c}\text { Calcium } \\
(\mathbf{m g} / \mathbf{d L})\end{array}$ & $\begin{array}{c}\text { Uric acid } \\
(\mathbf{m g} / \mathbf{d L})\end{array}$ & $\begin{array}{c}\text { Urea } \\
(\mathbf{m g} / \mathbf{d L})\end{array}$ & $\begin{array}{c}\text { Oxalate } \\
(\mathbf{m g} / \mathbf{d L})\end{array}$ \\
\hline Normal group & $2.09 \pm 1.40$ & $6.79 \pm 1.13$ & $3.83 \pm 1.86$ & $55.78 \pm 1.95$ & $8.15 \pm 1.19$ \\
Control group & $5.36 \pm 2.07 \mathrm{~b}$ & $18.93 \pm 1.45^{\mathrm{a}}$ & $7.97 \pm 0.90^{\mathrm{a}}$ & $71.51 \pm 2.13^{\mathrm{a}}$ & $16.08 \pm 1.40^{\mathrm{a}}$ \\
Standard group & $2.32 \pm 0.59^{*}$ & $12.18 \pm 1.60^{* * *}$ & $4.56 \pm 0.91^{* *}$ & $63.99 \pm 1.66^{* * *}$ & $9.10 \pm 1.39^{* * *}$ \\
TGI & $2.35 \pm 1.06^{*}$ & $14.10 \pm 1.98^{* * *}$ & $2.50 \pm 1.46^{* * *}$ & $68.22 \pm 1.21^{*}$ & $10.38 \pm 1.57^{* * *}$ \\
TGII & $2.87 \pm 1.22^{*}$ & $13.15 \pm 1.43^{* * *}$ & $1.99 \pm 1.34^{* * *}$ & $62.75 \pm 1.37^{* * *}$ & $8.37 \pm 2.31^{* * *}$ \\
\hline
\end{tabular}

Note: All the values of mean $\pm \mathrm{SD} ; \mathrm{n}=6$; Significant from control ${ }^{*} \mathrm{p}<0.05,{ }^{*} \mathrm{p}<0.01,{ }^{* * *} \mathrm{p}<0.001$; Significant from normal $\mathrm{a}=\mathrm{p}<0.001$ and $\mathrm{b}=\mathrm{p}<0.01$.

control group. On treatment with EET'T $400 \mathrm{mg} / \mathrm{kg} \mathrm{BW}$ and EET'T 200mg/kg BW, the elevated levels of these parameters were significantly reduced in TGs. Specifically the dose of EET'T $400 \mathrm{mg} / \mathrm{kg}$ BW showed significant reduction in concentration of the parameters like calcium, uric acid, urea, oxalate and EETT $200 \mathrm{mg} / \mathrm{kg}$ BW was effective in reducing the creatinine concentration in urine. In case of serum parameters, the dose of EETT $400 \mathrm{mg} / \mathrm{kg}$ BW showed significant reduction in the concentrations of calcium, urea, oxalate and the dose of EET'T $200 \mathrm{mg} / \mathrm{kg}$ BW was effective in reducing the creatinine and uric acid levels. 


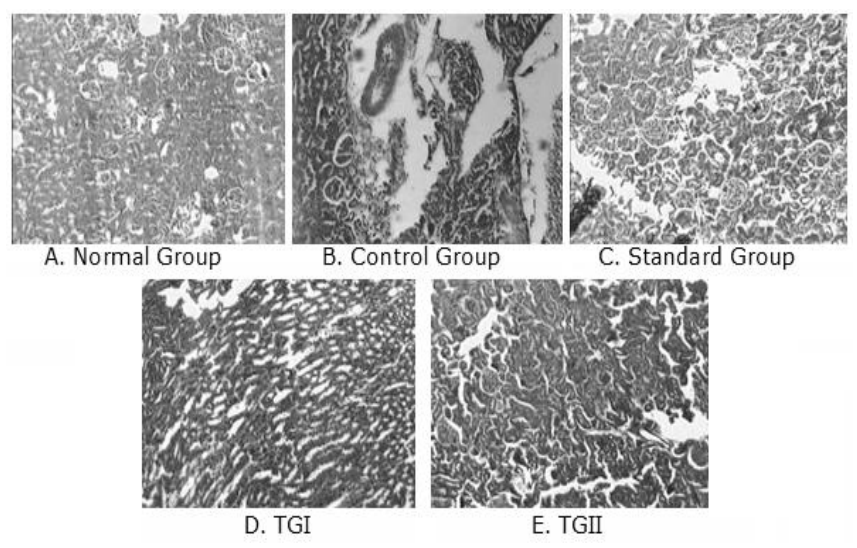

Figure 3. Histopathology of kidneys in various treatment groups. Animals had regular diet, B) Animals had regular diet + Supplemented with $0.75 \%$ EG and $2 \%$ AC in distilled water, C) Animals administered with CST $(5 \mathrm{~mL} / \mathrm{kg}$ BW), D) TGI Animals administered with EETT $200 \mathrm{mg} / \mathrm{kg}$ BW, E) TGI Animals administered with $400 \mathrm{mg} / \mathrm{kg}$ BW.

Table II. Effect of EETT on blood parameters in urolithiatic rats

\begin{tabular}{cccccc}
\hline \multirow{2}{*}{ Groups } & \multicolumn{5}{c}{ Blood parameters } \\
\cline { 2 - 6 } & $\begin{array}{c}\text { Creatinine } \\
(\mathbf{m g} / \mathbf{d L})\end{array}$ & $\begin{array}{c}\text { Calcium } \\
(\mathbf{m g} / \mathbf{d L})\end{array}$ & $\begin{array}{c}\text { Uric acid } \\
(\mathbf{m g} / \mathbf{d L})\end{array}$ & $\begin{array}{c}\text { Urea } \\
(\mathbf{m g} / \mathrm{dL})\end{array}$ & $\begin{array}{c}\text { Oxalate } \\
(\mathrm{mg} / \mathrm{dL})\end{array}$ \\
\hline Normal group & $1.0 \pm 0.68$ & $3.86 \pm 1.61$ & $4.05 \pm 1.47$ & $31.15 \pm 1.98$ & $2.87 \pm 1.02$ \\
Control group & $3.38 \pm 0.72^{\mathrm{a}}$ & $10.48 \pm 1.82^{\mathrm{a}}$ & $7.09 \pm 1.53^{\mathrm{c}}$ & $54 \pm 1.72^{\mathrm{a}}$ & $6.3 \pm 1.13^{\mathrm{b}}$ \\
Standard group & $1.78 \pm 0.81^{*}$ & $4.12 \pm 1.63^{* * *}$ & $3.91 \pm 1.04^{* *}$ & $44.96 \pm 1.73^{* * *}$ & $3.90 \pm 1.34^{*}$ \\
TGI & $0.55 \pm 0.16^{* * *}$ & $4.90 \pm 1.49^{* * *}$ & $1.80 \pm 1.47^{* * *}$ & $49.53 \pm 2.47^{* *}$ & $4.09 \pm 1.43^{*}$ \\
TGII & $2.52 \pm 0.96$ & $4.04 \pm 1.72^{* * *}$ & $2.00 \pm 1.64^{* * *}$ & $45.25 \pm 1.89^{* * *}$ & $2.83 \pm 1.52^{* *}$ \\
\hline
\end{tabular}

Note: All the values of mean $\pm \mathrm{SD}$; $\mathrm{n}=6$; Significant from control $*_{\mathrm{p}}<0.05,{ }^{*} \mathrm{p}<0.01,{ }^{* * *} \mathrm{p}<0.001$; Significant from normal $\mathrm{a}=\mathrm{p}<0.001, \mathrm{~b}=\mathrm{p}<0.01, \mathrm{c}=\mathrm{p}<0.05$.

The EETT also affects the physiological parameters like urine volume, urine $\mathrm{pH}$ and kidney weight (Table III). There was significant reduction in urine volume observed in control group animals compared to the normal group and TG animals. However, the elevation in urine volume was observed in TG animals but the dose of EETT $400 \mathrm{mg} / \mathrm{kg} \mathrm{BW}$ was considered as effective dose in enhancing the urine volume. The $\mathrm{pH}$ of the urine was found to be 6.9, 5.15 and 7.93 in normal, control and standard group animals respectively. TG animals (specifically TGI) were showed the urine $\mathrm{pH}$ closed to that of normal group. The kidney weight of normal group was about $0.55 \mathrm{~g}$ and it was greater in the case of control group animals. Among the TG animals, TGI showed the kidney weight closed to that of normal group.

\section{Histopathology}

The histopathological study of the kidney sections was supported the above findings. Histopathological profile of normal group animals showed normal renal peritubular interstitial architecture (Figure 3(A)). Control group animals showed inflammatory mediator infiltration, flattened epithelial cells with vacuolar degeneration, focal collecting duct cell necrosis with increased cast density in the peritubularinterstitium(Figure 3(B)). Micrograph section from standard group animals showed renal epithelial cell recovery and reduced cast density indicating the effectiveness of the treatment as evident by increased urine volume (Figure 3(C)). Micrograph of TG animals showing the renal epithelial cell recovery, reduced cast density, improved renal architecture (Figure 3(D \& E)) and it is 
Table III. Effect of EETT on physiological parameters in urolithiatic rats

\begin{tabular}{cccc}
\hline Groups & \multicolumn{3}{c}{ Physiological parameters } \\
\cline { 2 - 4 } & Urine volume $(\mathbf{m L})$ & Urine $\mathbf{p H}$ & Kidney weight $(\mathbf{g m})$ \\
\hline Normal group & $16.4 \pm 2.0$ & $6.9 \pm 0.45$ & $0.55 \pm 0.16$ \\
Control group & $6.73 \pm 0.79^{\mathrm{a}}$ & $5.15 \pm 3.09^{\mathrm{b}}$ & $2.29 \pm 0.31^{\mathrm{a}}$ \\
Standard group & $13.58 \pm 1.77^{* * *}$ & $7.93 \pm 0.86^{* * *}$ & $0.65 \pm 0.16^{* * *}$ \\
TGI & $9.87 \pm 2.15$ & $6.30 \pm 0.86$ & $0.7 \pm 0.51^{* * *}$ \\
TGII & $10.96 \pm 2.42^{* *}$ & $7.81 \pm 0.35^{* * *}$ & $1.03 \pm 0.53^{* * *}$ \\
\hline
\end{tabular}

Note: All the values of mean $\pm \mathrm{SD} ; \mathrm{n}=6$; Significant from control ${ }^{*} \mathrm{p}<0.01,{ }^{* * *} \mathrm{p}<0.001$; Significant from normal $\mathrm{a}=\mathrm{p}<0.001$ and $\mathrm{b}=\mathrm{p}<0.01$.

clearly evident by the biochemical parameters (Table I-III). However, the test EETT was found to be less significant compared to the standard group in producing renal tubular epithelial cell recovery.

Urinary stone formation takes place due to the changes in urinary chemistry, such as hyperoxaluria and hypercalciuria, leading to urinary super saturation, which later crystallized, aggregates and end up in stone formation (Hongshi, et al., 2013; Vishal and Jack, 2011). Male wistar rats were selected due to occurrence of kidney stones is more in males than females and its urinary system resemblance to that of humans (Prasad et al., 1993). Evidences in previous studies indicates that, in response to 15 days administration period of $0.75 \% \mathrm{v} / \mathrm{v}$ EG along with $2 \% \mathrm{w} / \mathrm{v}$ $\mathrm{AC}$ induces urinary stones in wistar rats forms renal calculi (Selvam et al., 2001; Atmani et al., 2003). Different components like calcium, urea, uric acid, oxalate and creatinine were increased tremendously in urolithiatic rats which were detected during pathogenesis of renal stones. Increased calcium level in urine is a factor favours the precipitation and nucleation of apatite or $\mathrm{CaOx}$ from urine and subsequent crystal growth. The increase in calcium deposition in kidney and its urinary excretion is due to the defective renal tubular reabsorption or an increase in absorption from the intestine as the patients with renal calcium stones were reported to have hyper absorption of calcium. (Hongshi et al., 2013; Vishal and Jack, 2011). Increased urinary calcium excretion along with stress of oxalate seems to provide an environment appropriate for the formation of stones by forming $\mathrm{CaOx}$ crystals, which epitaxially induces $\mathrm{CaOx}$ deposition (Patel et al., 2011). Treatment with EETT restores urinary phosphate levels, thereby reducing the risk of stone formation. In urolithiasis, the GFR decreases, due to the obstruction of urine out flow by stone in urinary system. The waste products, predominantly nitrogenous substances such as urea, creatinine and uric acid get accumulated in blood (Patel et al., 2011). In addition, increased lipid peroxidation and decreased level of potential of antioxidant had reported in kidneys of rats supplemented along with a diet which produces calculi (Sumathi et al., 1993; Saravanan et al., 1995). In this milieu, calcium has been reported to induce calculi and to cause renal tissue destruction by reacting with poly unsaturated fatty acids in the cell membrane (Hess, 2003). In the calculi induced rats, the increased serum levels of uric acid and creatinine indicates marked renal damage. However, antioxidant property of phytochemicals present in EETT hastens the procedure of dissolving the stones which were formed before in curative regimen and prevents the formation of new stone in excretory system on prophylactic treatment. Antiurolithiatic activity of many plants has been attributed to their high phenolic contents and particularly, flavonoids contain antiurolithiatic activity, which was evident from previous studies (Vayas et al., 2011; Shashank and Pandey, 2013). EETT consists of flavonoids in high concentration when compared to the alkaloids and tannins. Hence, it indicates that the antiurolithiatic activity of EET'T might be due to the presence of flavonoids in extract. 
Antiurolithiatic activity of EETT was also supported by histopathological observations. The markedly elevated serum levels of creatinine, urea, uric acid, oxalate, calcium in stone forming animals were indicative of prominent necrosis of renal epithelia. In the calculi induced animals, there was damage to the last part of nephron. Elevated levels of oxalate in urine and even its retention in kidneys may one of the causative factors for the peroxidative degeneration of renal epithelia. However the curative and preventive treatment with ethanolic extract of whole plant of Taxillus tomentosus prevented the stone formation as evident by various biochemical parameters.

\section{CONCLUSION}

It was concluded from the results that the administration of EET'T whole plant into the EG and AC induced urolithiatic rats reduced the formation of urinary stones. The mechanisms underlying this effect is still unknown, but apparently related to diuresis and lowering of urinary concentration of stone forming constituents. Hence, the present study has showed the antiurolithiatic potential of EETT by the mechanisms to be deciphered in future course of study.

\section{ACKNOWLEDGMENT}

The authors wish to thank for the support received from Department of botany, Sri Venkateswara University, Tirupati, Andhra Pradesh, India Prof. M. Madhava chetti.

\section{REFERENCES}

Atmani F., Slimani Y., Mimouni M., and Hacht B. 2003. Prophylaxis of calcium oxalate stones by Herniaria hirsuta on experimentally induced nephrolithiasis in rats. Brit. J.Ur. Int. 92:137-140.

Fleisch H. 1978. Inhibitors and promoters of stone formation. Kid. Int. 13: 361-71.

Hess B. 2003. Pathophysiology, diagnosis and conservative therapy in calcium kidney calculi. Therapeutische Umschau. 60: 79-87.

Hodgkinson A. 1970. Determination of oxalic acid in biological material. Clin. Chem. 16:547-57

Hongshi X., Anna LZ., Fredric LC., and Elaine MW. 2013. Kidney stones: an update on current pharmacological management and future directions. Expert Opinion on Pharmacotherapy 14: 435-447.

Karadi RV., Gadge NB., Alagawadi KR., and Savadi RV. 2006. Effect of Moringa oleifera Lam. root-wood on ethylene glycol induced urolithiasis in rats. J. Ethnopharmacology 105: 306-11.

Khandelwal KR. 2005. Practical Pharmacognosy Techniques and Experiments. Pune: Nirali Prakashan.

Mitra SK., Gopumadhavan S., Venkataranganna MV., and Sundaram R. 1988. Effect of cystone, a herbal formulation, on glycolic acid-induced urolithiasis in rats. Phytotherapy Res. 12: 372-4.

Mohammed NU., Mohammed WU., and Firasath A. 2015. Evaluation of diabetic complications, neuro, hepato, cardio and nephron protective effects of ethanolic extract of the whole plant of Taxillus tomentosus in alloxan induced diabetic rats. Eur. J.Phar.and Med. Rese.2: 410-36.

Parasuraman S., Raveendran R., and Kesavan R. 2010. Blood sample collection in small laboratory animals. J.Pharmacology and Pharmacotherapeutics 1: 87-93.

Patel PK., Patel MA., Saralai MG., and Gandhi TR. 2012. Antiurolithiatic Effects of Solanum xanthocarpum Fruit Extract on Ethylene-Glycol-Induced Nephrolithiasis in Rats. J.Young Pharmacists 4: 164-170.

Patel RK., Patel SB., and Shah JG. 2011. AntiUrolithiatic activity of ethanolic extract of seeds of Benincasa hispida (Thumb). Pharmacologyonline 3: 586-591.

Prasad KVSRG., Bharathi K., and Srinivasan KK. 1993. Evaluation of Musa parasidica Linn Cultivar)-"Puttubale" stem juice for antilithiatic activity in albino rats. Ind. J.Physiology and Pharmacology 37: 337-41.

Rivers K., Shetty S., and Menon M. 2000. When and how to evaluate a patient with nephron-lithiasis. Urologic Clinics of North America 27: 203-13.

Saravanan N., Senthil D., and Varalakshmi P. 1995. Effect of 1-cysteine on lipid peroxidation in experimental urolithiatic rats. Pharmacological Research 32: 165-169. 
Selvam P., Kalaiselvi P., Govindaraj A., Murugan VB., and Sathishkumar AS. 2001. Effect of $A$. lanata leaf extract and vediuppu chunnam on the urinary risk factors of calcium oxalate urolithiasis during experimental hyperoxaluria. Pharmacological Research 43: 89-93.

Shashank K., and Pandey AK. 2013. Chemistry and Biological Activities of Flavonoids: An Overview. Sci. Wor. J. 2013; 1-32.

Silpa S., Jamal U., and Jayasekhar VL. 2014. Screening of Taxillus Tomentosus Ethanolic Extract for Nootropic and Antistress Activity in Rats. International J. Innov and Applied Studies 8: 1533-1544.

Sumathi R., Jayanthi S., Kalpanadevi V., and Varalakshmi P. 1993. Effect of DL- $\alpha-$ lipoic acid on tissue lipid peroxidation and antioxidant systems in normal and glycollate treated rats. Pharmacological Research 27: 1-10.

Tandon PN., Mahajan RC., Anand N., Basu SK., Ganguly NK. et al. 2000. Guideline for the care and use of animals in scientific research, revised edition. New Delhi: Indian National Science Academy. Touhami M., Laroubi A., Elhabazi K., Loubna F., Zrara I., and Chait A. 2007. Lemon juice has protective activity in a rat urolithiasis model. BMC Urology 7: 1-8.

Venkateswarlu K., Vijayabhaskar K., Krishna OS., Devanna N., and Chandrasekhar KB. 2015. Evaluation of anti-ulcer activity of hydro alcoholic extracts of Abutilon indicum, Helianthus annuus and combination of both against ethanol and pyloric ligation induced gastric ulcer in albino wistar rats. Brit. J.Pharm.Res.5: 4251.

Vishal NR., and Jack GK. 2011. Mechanisms of Stone Formation. Clin. Reviews in Bone and Mineral Metabolism 9: 187-97.

Vyas BA., Vyas RB., Joshi SV., and Santani DD. 2011. Antiurolithiatic Activity of Whole-Plant Hydroalcoholic Extract of Pergularia daemia in Rats. J. Young Pharm. 3: 36-40. 